\title{
Suriyeli Mültecilerin Çeşitli Travmatik Yaşantıları Nasıl Deneyimlediklerine Göre Travma Sonrası Stres Bozukluğu ve Yaşam Doyum Düzeylerinin İncelenmesi
}

DOI: $10.26466 /$ opus.658813

\author{
Demet Bilen* - Binnaz Kıran** \\ * PIKTES Öğrt., Zeki Sabah İlkokulu, Mersin/Türkiye \\ E-Posta: demtbilen@gmail.com \\ ORCID: $\underline{0000-0002-3688-2979}$ \\ ** Prof. Dr., Mersin Üniversitesi Eğitim Fakültesi, Mersin/Türkiye \\ E-Posta: binkiran2009@gmail.com \\ ORCID: $\underline{0000-0002-9027-2872}$
}

Öz

Bu araştırmada Suriyeli mültecilerin çeşitli travmatik yaşantıları nasıl deneyimlediklerine göre yaşam doyumu ve travma sonrası stres bozukluğu düzeylerinin farklılı gösterip göstermediği incelenmiştir. Ayrica Suriyeli mültecilerin yaşam doyumlarının travma sonrası semptom bozukluğu olup olmamasına göre farklllık gösterip göstermediği de incelenmiştir. Bu araştırmada kullanılan veri toplama formu; "Sosyo-Demografik Bilgi Formu, Travmatik Olaylar Listesi, Harvard Travma Ölçeği (HTÖ) ve Yaşam Doyumu Ölçeği (YDÖ)" olmak üzere toplam 4 bölümden oluşmaktadır. Ölçme araçlarının Arapça dili açısndan geçerli olup olmadığııı belirlemek amacıyla 32 kişilik bir Suriyeli mülteci grubuyla pilot uygulama gerçekleştirilmiş̧ir. 18 yaş üstü 590 Suriyeli mülteciden oluşan katılımcıların 325'i kadın, 265'i ise erkektir. Araştırma sonucunda çeşitli travmatik olayları yaşayan/tanık olan mültecilerin şehrin bombalanması dışında diğer durumların hepsinde maruz kalmayanlara göre travma sonrası stres bozukluk düzeylerinin anlamlı olarak daha yüksek olduğu bulunmuştur. Belirli travmatik olaylara maruz kalma ile travma sonrası stres bozukluğu düzeyi arasında anlamlı pozitif bir farklılı gözlenirken; yaşam doyumu düzeyi arasında anlaml negatif bir farklllı gözlenmiştir. Ayrıca travma sonrası stres bozukluğu semptomlar gösteren mültecilerin yaşam doyum düzeyleri, semptomları göstermeyen mültecilere göre düşük olmuştur. Çalışmanın bulgularn ilgili literatür çerçevesinde tartışma bölümünde değerlendirilmişstir. Illerde mültecilerle yapılacak bilimsel çalışmalar için umut, yaşam kalitesi, psikolojik dayanıkllık gibi pozitif psikoloji değişkenlerin ele alınması önerilmiştir.

Anahtar Kelimeler: Savaş, mülteci, travma, travma sonrası stres bozukluğu, yaşam doyumu 


\title{
Investigation of Post-Traumatic Stress Disorder and Life Satisfaction Levels According to How Syrian Refugees Experience Various Traumatic Experiences
}

\begin{abstract}
In this study, it was investigated whether the levels of posttraumatic stress disorder and life satisfaction differ according to how Syrian refugees experience various traumatic experiences. Also, it has been investigated whether the life satisfaction of Syrian refugees varies according to the presence of post-traumatic symptom disorder or not. The data collection form used in this study is comprised of a total of 4 chapters; namely "Socio-Demographic Form, Traumatic Events List, Harvard Trauma Questionnaire (HTQ) and Satisfaction With Life Scale (SWLS)". A pilot application was carried out with a group of 32 Syrian refugees to test the measurement instruments' compliance with standard Arabic. The research participants consisted of 590 Syrian refugees over the age of 18. Of the participants, 325 are female Syrian refugees while 265 are male Syrian refugees. As a result of the research, it was found that the refugees who experienced/witnessed various traumatic events had significantly higher levels of posttraumatic stress disorder than those who were not exposed in all other situations except the bombing of the city. In addition, while a significant positive difference was observed between exposure to certain traumatic events and posttraumatic stress disorder level, a significant negative difference was observed between life satisfaction level. In addition, the life satisfaction levels of the refugees who showed symptoms of posttraumatic stress disorder were lower than the refugees who did not show the symptoms. The findings of the study were evaluated in the discussion section within the framework of the relevant literature. It is suggested that positive psychology variables such as hope, quality of life, and psychological resilience should be addressed for future scientific studies with refugees.
\end{abstract}

Keywords: War, refugee, trauma, post- traumatic stress, life satisfaction 


\section{Giriş}

Günümüzde uzun süren çatışma ortamı ile zorla yerinden edilme ve mülteci hareketleri, Birleşmiş Milletlerin kuruluşundan beri görülmemiş bir düzeye varmış bulunmaktadır. Birleşmiş Milletler Mülteci Yüksek Komiserliğinin (UNHCR) kayıtlarına göre dünyada altmış sekiz milyondan fazla insan çatışma, şiddet ve insan hakları ihlalleri ile yerinden edilmiştir (UNHCR, 2018a). Dünya genelinde yaşadıkları yerde iç savaş ve baskı gibi zorlayıcı nedenlerle göç etmek zorunda kalan insanlar artış gösterirken 2016 yılı itibariyle Türkiye bünyesindeki mülteci sayısı bakımından birinci sırada yer almaktadır (UNHCR, 2018b). Bu durum büyük oranda Suriye' de 2011 yılında ortaya çıkan çatışmalar nedeniyle burada yaşayan insanların yaşam mücadelesi vererek komşu ülker gitmesi ile bağlantılıdır. Bu insanlarım yaklaşık üç milyonu Türkiye' ye sığınmıştır (UNHCR, 2018c).

Kapsam ve şiddetine göre savaşlar, bireysel ve kitlesel yaşama son verdiği gibi savaştan kurtulan bireylerde uzun süreli fiziksel ve ruhsal sorunlara neden olmaktadır. Ampirik çalışmalar, savaşın beraberinde getirdiği zorunlu göçe tabi tutulmuş mültecilerde, savaşın doğrudan veya dolaylı olarak yol açtığı ruhsal rahatsızlıklardan Travma Sonrası Stres Bozukluğu (TSSB) geliştiğini göstermektedir (Erickson, Wolfe, King, King ve Sharskansky, 2001; Johnson ve Thompson, 2008; Solomon, Weisemberg, Schwarzwald ve Milkulincer, 1987). Literatürdeki yerini 2. Dünya Savaşı' ndan sonraki yıllarda alan TSSB, şiddetli bir boyutta yaşanan travmatik bir süreç ile ortaya çıkan ve travma sonrasında travmaya bağlı gelişen çeşitli belirtiler ile kendini gösteren bir rahatsızlıktır (Özgen ve Aydın, 1999). TSSB' den etkilenen ruh sağlığı, bireyin yaşam kalitesini büyük orandan etkileyebilmektedir. TSSB gözlenen bireylerin yaşam koşullarının daha olumsuz olduğu ve yaşam doyumlarının daha düşük olduğu gözlenmiştir (Schnurr, Lunney, Bovin ve Marx, 2009).

Öznel iyi oluş, insanların kendi hayatlarını bir bütünen subjektif bir boyutta muhakeme etmesi şeklinde ifade edilmektedir. Yaşam doyumu, öznel iyi oluşun üç temel bileşeninden biridir (Diener, 1984). Yaşam doyumu, insanların kendi bireysel ölçütlerini baz alarak ideal olarak nitelediği yaşam ile kendi yaşamının niteliğini bir bütün olarak görebilmesidir (Christopher, 1999; Diener, Emmons, Larsen ve Griffin, 1985; Veenhoven, 1996).

Kişilerin yaşamlarından aldıkları doyumun yüksekliği kişinin yalnızca kendini daha iyi hissetmesi ve daha olumlu ilişkilere sahip olduğunu (Diener 
ve Seligman, 2002) göstermez. Bunların yanında kişinin yaşam sevincinin arttığı, özgün düşünme becerisinin geliştiği, yaşam süresinin uzadığ sisteminin güçlendiği görülmektedir (Lyubomirsky, King ve Diener, 2005). Özellikle öznel iyi oluş göz önüne alındığında bireylerin yaşam doyumu, stresli yaşam olayların baskılayıcı psikolojik bir güçtür (Suldo ve Huebner , 2004). Bu tamponlama etkisi, psikolojik sorunların gelişim riskine karşı koruyucu bir etken olarak yaşam doyumu potansiyelini göstermektedir. Bu anlamda, TSSB' nin yaratacağı olumsuzlukların ve yaşam doyumunun incelenmesi önem taşımaktadır.

Yukarıda belirtilen nedenlerden ötürü bu araştırmanın temel amacı, Suriyeli mültecilerin çeşitli travmatik yaşantıları nasıl deneyimlediklerine (yaşama/tanık olma) göre TSSB ve yaşam doyumlarının farklılık gösterip göstermediğini araştırmaktır. Buradan yola çıkarak oluşturulan araştırma soruları şunlardır:

1. Suriyeli mültecilerin çeşitli travmatik olayları nasıl deneyimlediklerine (yaşama/tanık olma) göre travma sonrası semptom düzeyleri farklılık göstermekte midir?

2. Suriyeli mültecilerin çeşitli travmatik olayları nasıl deneyimlediklerine (yaşama/tanık olma) göre yaşam doyumları farklılık göstermekte midir?

3. Suriyeli mültecilerin yaşam doyumları, travma sonrası stres bozukluğuna sahip olup ya da olmamalarına göre farklılık göstermekte midir?

\section{Yöntem}

\section{Çalışma Grubu}

$\mathrm{Bu}$ araştırmada çalışma grubu, olasılıksız örnekleme yöntemlerinden kartopu örnekleme tekniğiyle oluşturulmuştur. Araştırma Mersin il merkezinde bulunan dört merkezi ilçede (Akdeniz, Yenişehir, Mezitli, Toroslar) yürütülmüştür. Araştırmaya katılan 18 yaş üstü 623 Suriyeli mülteci ile yapılan çalışma verileri üzerinde yapılan kayıp veri ve uç değer analizi sonrası 590 mültecinin verileri analize dahil edilmiştir.

Araştırmaya katılan Suriyeli mültecilerin \%55,1'i (n=325) kadın, \%44,9'u $(n=265)$ erkektir. Katılımcılar arasında en çok gözlenen yaş grubu 18-24 yaş iken (\%32,); en az gözlenen yaş grubu ise 53 yaş ve üstü mültecilerdir $(\% 3,1)$. 
Suriyeli mültecilerin \%66,3'ü ( $\mathrm{n}=391)$ evli, \%33,7'si (n=199) bekardır. Katılımcllar arasında lise mezunu olanların $\% 32,0(n=189)$ değeriyle diğer eğitim durumlarına göre en yüksek oranda olduğu; $\% 3,7^{\prime} \operatorname{sinin}(n=22)$ ise okuryazar düzeyde olduğu tespit edilmiştir.

\section{Veri Toplama Araçları}

Bu araştırmada "Sosyo- Demografik Bilgi Formu", "Travmatik Olaylar Listesi", "Harvard Travma Ölçeği (HTÖ)" ve "Yaşam Doyumu Ölçeği (YDÖ)” kullanılmıştır. Uygulama öncesinde veri toplama araçlarındaki her bir madde Arapça anlaşılırlığının test edilmesi ile ilgili olarak Arapça ve Türkçe dillerini iyi bilen dört farklı tercümanla değerlendirilmiştir. Değerlendirme esnasında veri toplama araçlarının Türkçe, İngilizce ve Arapça versiyonları birbirleriyle karşılaştırılmıştır. Bununla birlikte araştırmanın yapılacağı il merkezinde bulunan bir ilçede (Yenişehir) 32 kişilik bir Suriyeli mülteci grubuyla pilot uygulama gerçekleştirilmiştir. Pilot uygulama esnasında herhangi bir sorun çıkmamıştır.

Sosyo-Demografik Bilgi Formu: Kişisel bilgileri içeren ve toplam 7 maddeden oluşan bu form araştırmacılar tarafından hazırlanmıştır.

Travmatik Olaylar Listesi: Türkçe hazırlanıp, Türkçe-Arapça-İngilizce dillerini bilen iki tane yeminli tercüman tarafından Arapça, Türkçe ve İngilizce çevirileri yapılarak kontrol edilen bu form, savaş ve göç mağduru katılımc1ların yaşadıkları/tanık oldukları travmatik yaşantıları değerlendirmeyi amaçlamıştır (Yeniçeri, 2017). Form maddeleri, pilot uygulama sonrası benzer olayların çıkarılmasıyla 23 maddeden, 11 maddeye düşürülerek kullanılmıştir.

Harvard Travma Ölçeği (HTÖ IV. Bölüm- Travma Semptomlarn): Ölçek mültecilerin başlarından geçen travmatik olayları ve travma sonrası stres bozukluğu belirtilerini DSM kriterleri dahilinde belirleme amaçlı geliştirilmiştir (Mollica vd., 1992). HTÖ, kültürel duyarlılığa sahip olması ile farklı kültürel yapılardaki mülteci topluluklarında travma ve travma ile ilgili semptomları ölçmek amacıyla geliştirilmiş tek araçtır (Mollica, Mcdonald, Massagli ve Si- 
love, 2004). Ölçeğin Arapça dilindeki uyarlaması 2007 yılında Shoeb ve arkadaşları tarafından geliştirilmiştir (Shoeb, Weinstein, ve Mollica, 2007). Çeşitli dillerde versiyonu bulunan ölçeğin bu çalışmada kullanılan Arapça versiyonu İşkence Kurbanları Rehabilitasyon Komisyonu tarafından test edilmiştir (Vindbjerg, Carlsson, Mortensen, Elklit ve Makransky, 2016). Bu araştırmada ölçeğin Cronbach Alpha katsayısı 0,92 olmuştur.

Yaşam Doyumu Ölçeği(YDÖ): Diener vd. (1985) 7'li Likert tipinde ve toplamda 5 madde içeren kendini değerlendirme ölçeği olan yaşam doyumu ölçeğini geliştirmiştir (Diener vd., 1985). Ölçek, psikopatolojiye ve duygusal iyi oluşa odaklanan ölçeklerin tamamlayıcısı olarak önerilmektedir (Pavot ve Diener, 1993). Ölçeğin Arapça geçerlik ve güvenirlik çalışmasını yaparak Arapça versiyonu geliştiren Taisir Abdallah (1998 ) çalışmasında YDÖ’ nün evrensel olduğunu ve farklı kültürlerde uygulanabileceğini ifade etmiştir (Abdallah, 1998). Ölçeğin Cronbach Alfa güvenirlik katsayısı bu araştırma için 0,75 'tir.

\section{Verilerin Analizi}

Öncelikle verilerin, normal dağılıp dağılmadıkları incelenmiştir. Gözlem sayısının otuzun altında olduğu durumlarda Shapiro-Wilk testi , olmadığı durumlar için ise Kolmogorov Smirnov testi sonuçları dikkate alınmıştır. Travma sonrası semptom düzeyinin ve yaşam doyumlarına ait puanların travmatik olaylar listesindeki değişkenler açısından dağılımının normal olmadığ gözlenmiştir $(\mathrm{p}<0,05)$. Bu nedenle değişkenler arasında fark olup olmadığına Bonferroni düzeltmesine dayalı Mann Whitney U testi ile bakılmıştır. Suriyeli mültecilerde travma sonrası stres bozukluğu görülüp görülmemesine göre yaşam doyumlarının incelenmesi için de Mann Whitney U testi kullanılmıştır. Çalışmada $\alpha=0,05$ olarak hesaplanmıştır.

\section{Bulgular}

Bu bölümde travma sonrası semptomlara ve yaşam doyumuna ilişkin ölçeklerden elde edilen puanların dağılımına ve araştırma sorularının her birine ilişkin bulgular yer almaktadır. Suriyeli mültecilerin Harvard Travma ve Yaşam Doyumu Ölçeği'nden aldıkları puanların dağlımı Tablo 1'de verilmiştir. 
Tablo 1. Travma sonrası semptom düzeyi ve yaşam doyumu puanlarının dağılımına ilişkin bazı istatistikler

\begin{tabular}{lll}
\hline Değişkenler & Travma & Yaşam Doyumu \\
\hline $\mathrm{N}$ & 590 & 590 \\
Ortalama & 88,79 & 19,74 \\
Ortanca & 89,00 & 20,00 \\
Mod & 59,00 & 20,00 \\
Standart sapma & 20,98 & 6,06 \\
Varyans & 440,12 & 36,70 \\
Çarpıklık &, 107 &,- 031 \\
Çarpıklı̆̆ın st. Hatası &, 101 &, 101 \\
Basıklık &,- 723 &,- 555 \\
Basıklı̆̆n st. Hatası &, 201 &, 201 \\
Değişim aralı̆̆ & 98,00 & 30,00 \\
En düşük puan & 45,00 & 5,00 \\
En yüksek puan & 143,00 & 35,00 \\
\hline Kolmogorov Smirnov &, 044 &, 056 \\
sd & 590 & 590 \\
p &, 008 &, 000 \\
\hline Cronbach $\alpha$ & 0,921 & 0,746 \\
\hline
\end{tabular}

Tablo 1. incelendiğinde her iki değişken içinde dağılımın tam simetrik ancak normale göre daha basık bir dağılım olduğunu görülmektedir. Aynı zamanda her iki dağılımın da normal olmadığı görülmektedir.

\section{Suriyeli Mültecilerin Çeşitli Travmatik Olayları Nasıl Deneyimlediklerine (Yaşama/Tanık Olma) Göre Travma Sonrası Semptom Düzeylerinin Incelenmesi}

Suriyeli mültecilerin, travma sonrası semptom düzeylerinin, çeşitli travmatik olayları nasıl deneyimlediklerine (yaşama/tanı olma) göre farklılık gösterip göstermediğini belirlemek amacıyla, her olay grubu için ayrı ayrı olmak üzere, ilişkisiz örneklemler için kullanılan Kruskall Wallis testine göre analiz sonuçları, Tablo 2' de verilmiştir. 
Tablo 2. Suriyeli mültecilerin çeşitli travmatik olaylar nasıl deneyimlediklerine (yaşama/tanı olma) göre travma sonrası semptom düzeylerine ilişkin Kruskall Wallis testi sonuçları

\begin{tabular}{|c|c|c|c|c|c|c|c|}
\hline Travmatik olaylar & Düzeyler & $\bar{X}$ & ortanca & Sira ort & $\chi^{2}$ & $\mathrm{p}$ & fark \\
\hline \multirow{4}{*}{$\begin{array}{l}\text { Yaşanılan evin } \\
\text { bombalanması }\end{array}$} & Yaşanan & 92,33 & 94,00 & 324,14 & \multirow{4}{*}{24,945} & \multirow{4}{*}{0,000} & \multirow{4}{*}{$\begin{array}{l}1-4 \\
2-4 \\
3-4\end{array}$} \\
\hline & Tanık olunan & 87,15 & 86,00 & 281,81 & & & \\
\hline & Her ikisi & 82,58 & 80,00 & 242,47 & & & \\
\hline & Hiçbiri & 78,28 & 79,00 & 212,60 & & & \\
\hline \multirow{4}{*}{$\begin{array}{l}\text { Yaşanılan şehrin bomba- } \\
\text { lanması }\end{array}$} & Yaşanan & 89,89 & 90,50 & 304,45 & \multirow{4}{*}{5,753} & \multirow{4}{*}{0,124} & \multirow{4}{*}{-} \\
\hline & Tanık olunan & 86,59 & 85,00 & 276,96 & & & \\
\hline & Her ikisi & 82,10 & 79,00 & 240,83 & & & \\
\hline & Hiçbiri & 89,46 & 88,00 & 305,31 & & & \\
\hline \multirow[t]{4}{*}{ Silahlı saldırı } & Yaşanan & 93,68 & 96,00 & 336,36 & \multirow{4}{*}{47,027} & \multirow{4}{*}{0,000} & \multirow{4}{*}{$\begin{array}{l}1-4 \\
2-4 \\
3-4\end{array}$} \\
\hline & Tanık olunan & 90,78 & 91,00 & 310,59 & & & \\
\hline & Her ikisi & 97,00 & 97,00 & 364,40 & & & \\
\hline & Hiçbiri & 78,46 & 77,00 & 212,05 & & & \\
\hline \multirow[t]{4}{*}{ Hafif yaralanma } & Yaşanan & 95,63 & 97,00 & 351,90 & \multirow{4}{*}{49,069} & \multirow{4}{*}{0,000} & \multirow{4}{*}{$\begin{array}{l}1-4 \\
2-4 \\
3-4\end{array}$} \\
\hline & Tanık olunan & 89,82 & 91,00 & 302,35 & & & \\
\hline & Her ikisi & 101,71 & 108,00 & 405,21 & & & \\
\hline & Hiçbiri & 79,58 & 79,00 & 222,09 & & & \\
\hline \multirow[t]{4}{*}{ Ağır yaralanma } & Yaşanan & 97,72 & 99,00 & 371,05 & \multirow{4}{*}{50,965} & \multirow{4}{*}{0,000} & \multirow{4}{*}{$\begin{array}{l}1-4 \\
2-4 \\
3-4\end{array}$} \\
\hline & Tanık olunan & 91,21 & 92,00 & 313,94 & & & \\
\hline & Her ikisi & 104,00 & 111,00 & 434,33 & & & \\
\hline & Hiçbiri & 79,94 & 79,00 & 224,21 & & & \\
\hline \multirow{4}{*}{$\begin{array}{l}\text { Yakın çevreden birinde } \\
\text { kalıcı sakatlanma/ iz bıra- } \\
\text { kan yaralanma }\end{array}$} & Yaşanan & 92,51 & 94,00 & 324,70 & \multirow{4}{*}{41,141} & \multirow{4}{*}{0,000} & \\
\hline & Tanık olunan & 87,86 & 88,00 & 288,29 & & & $\begin{array}{l}1-4 \\
2-4\end{array}$ \\
\hline & Her ikisi & 77,36 & 67,50 & 202,68 & & & $\begin{array}{l}2-4 \\
3-4\end{array}$ \\
\hline & Hiçbiri & 74,43 & 64,50 & 183,02 & & & \\
\hline Yakın çevreden & Yaşanan & 92,42 & 94,00 & 324,83 & & & $1-2$ \\
\hline birinin doğal olmayan/ & Tanık olunan & 86,83 & 86,00 & 278,88 & 2037 & $\cap \cap \cap \cap$ & $1-4$ \\
\hline beklenmedik vefatı & Her ikisi & 84,26 & 87,00 & 259,76 & $02,03 /$ & 0,000 & $2-4$ \\
\hline & Hiçbiri & 66,96 & 60,50 & 120,36 & & & $3-4$ \\
\hline İşkence/ dövülme & Yaşanan & 92,84 & 94,00 & 327,79 & & & \\
\hline & Tanık olunan & 92,36 & 93,50 & 323,61 & 43750 & $0 \cap 00$ & $\begin{array}{l}1-4 \\
2-4\end{array}$ \\
\hline & Her ikisi & 106,67 & 111,00 & 457,17 & 43,150 & 0,000 & $\begin{array}{l}2-4 \\
3-4\end{array}$ \\
\hline & Hiçbiri & 80,13 & 79,00 & 226,67 & & & \\
\hline Rehin alınma/ & Yaşanan & 92,56 & 94,00 & 327,83 & & & \\
\hline tutuklanma & Tanık olunan & 92,60 & 94,00 & 325,02 & 41283 & 0000 & $1-4$ \\
\hline & Her ikisi & - & - & 512,50 & 41,283 & 0,000 & $2-4$ \\
\hline & Hiçbiri & 80,70 & 80,00 & 231,06 & & & \\
\hline Cinsel şiddet & Yaşanan & 93,98 & 96,00 & 338,64 & & & \\
\hline & Tanık olunan & 92,50 & 94,00 & 324,75 & 32005 & $0 \cap 00$ & $1-4$ \\
\hline & Her ikisi & - & - & 512,50 & 32,005 & 0,000 & $2-4$ \\
\hline & Hiçbiri & 82,80 & 81,50 & 247,65 & & & \\
\hline Mallarına el konulması & Yaşanan & 93,54 & 95,00 & 333,89 & & & \\
\hline /gasp & Tanık olunan & 91,66 & 92,50 & 318,37 & 56,415 & 0,000 & $2-4$ \\
\hline & Her ikisi & 92,10 & 93,00 & 318,75 & 56,410 & 0,000 & $\begin{array}{l}2-4 \\
3-4\end{array}$ \\
\hline & Hiçbiri & 77,54 & 75,50 & 205,16 & & & \\
\hline
\end{tabular}


Tablo 2'ye bakıldığında, yalnızca yaşanılan şehrin bombalanması olayına göre Suriyeli mültecilerin travma sonrası semptom düzeylerinde bir farklılık olmadığı belirlenmiştir ( $p>0,05)$. Rehin alınma/tutuklanma ve cinsel şiddet olaylarında ise olayı yaşayan ve hiç yaşamayanların semptom düzeylerine ilişkin dağılımlar ve olaya tanık olanla hiç tanık olmayanların semptom düzeylerine ilişkin dağılımlar manidar bir farklılık göstermektedir $(\mathrm{p}<0,05)$. Yaşanılan evin bombalanması, silahlı saldırı, hafif ve ağır yaralanma, yakın çevresinden birilerinde kalıcı sakatlanma/iz bırakan yaralanma, yakın çevresinden birilerinin doğal olmayan/ani vefatı gibi olayların semptom düzeyleri incelendiğinde olayı yaşayan, tanık olan ya da her ikisini yaşayanların semptom düzeylerinin, hiç yaşamayanlara göre belirgin farklılıklar gösterdiği gözlenmektedir. Buna ek olarak, yaşanılan evin bombalanması olayında olayı yaşayanlarla hiç yaşamayanların semptom düzeylerinin farklı olduğu bulunmuştur $(p<0,05)$. Yakın çevresinden birilerini kaybedenlerde ise olayı yaşayanlar ile hiç yaşamayanların semptom düzeylerine ilişkin dağılımlar farkl1lık göstermektedir $(p<0,05)$.

\section{Suriyeli Mültecilerin Yaşam Doyumlarmm, Çeşitli Travmatik Olaylarn Nasıl Deneyimlediklerine (Yaşama/Tanık Olma) Göre İncelenmesi:}

Tablo 3'e göre, yaşanılan evin bombalanması, yaşanılan şehrin bombalanması ve yakın çevresinden birilerinin doğal olmayan beklenmedik kaybı olaylarına göre Suriyeli mültecilerin yaşam doyumu düzeylerinde bir farkl1lık olmadığı belirlenmiştir ( $p>0,05)$. Silahlı saldırı, hafif ve ağır yaralanma ve işkence/dövülme olaylarında olayı yaşayan, tanık olan ya da her ikisini yaşayanların semptom düzeylerinin, hiç yaşamayanlara göre manidar farklılık gösterdiği gözlenmektedir $(\mathrm{p}<0,05)$. Rehin alınma/tutuklanma ve cinsel şiddet olaylarında ise, olayın kendisini yaşayan ve hiç yaşamayanların semptom düzeylerine ilişkin dağılımların ve olaya tanık olan ve hiç yaşamayanların semptom düzeylerine ilişkin dağılımların ve manidar farklılık gösterdiği belirlenmiştir $(p<0,05)$. Yakın çevreden birinde kalıcı sakatlanma/iz bırakan yaralanma olayında, olayın kendisini yaşayanlarla böyle bir olayı hiç yaşamayanların yaşam doyum düzeylerinde manidar bir farklılık bulunmaktadır $(p<0,05)$. Mallarına el konulmasi/gasp olayında ise, olaya tanık olanlar ve 
hem tanık olup hem yaşayanların yaşam doyum düzeylerinin hiç yaşamayanlara göre manidar farklılık gösterdiği gözlenmektedir. Buna ek olarak mallarına el konulması/gasp olayının kendisini yaşayanlarla olaya tanık olanların semptom düzeylerine ilişkin dağılımların ve manidar farklılık gösterdiği belirlenmiştir $(\mathrm{p}<0,05)$.

Tablo 3. Suriyeli mültecilerin çeşitli travmatik olaylan nasıl deneyimlediklerine (yaşama/tanık olma) göre yaşam doyumlarnın ilişkin Kruskall Wallis testi sonuçları

\begin{tabular}{|c|c|c|c|c|c|c|c|}
\hline Yaşanılan olaylar & Düzeyler & $\bar{X}$ & ortanca & Sira ort & $\chi^{2}$ & $\mathrm{P}$ & fark \\
\hline \multirow[t]{4}{*}{ Yaşanılan evin bombalanması } & Yaşanan & 19,51 & 20,00 & 291,02 & 3,811 & \multirow{4}{*}{0,283} & \multirow{4}{*}{-} \\
\hline & Tanık olunan & 19,68 & 19,00 & 289,76 & & & \\
\hline & Her ikisi & 21,42 & 22,00 & 348,37 & & & \\
\hline & Hiçbiri & 20,61 & 21,00 & 323,61 & & & \\
\hline \multirow{4}{*}{$\begin{array}{l}\text { Yaşanılan şehrin bombalan- } \\
\text { ması }\end{array}$} & Yaşanan & 19,52 & 20,00 & 290,20 & 1,655 & \multirow{4}{*}{0,647} & \multirow{4}{*}{-} \\
\hline & Tanik olunan & 19,11 & 20,00 & 305,64 & & & \\
\hline & Her ikisi & 20,57 & 21,00 & 320,12 & & & \\
\hline & Hiçbiri & 20,46 & 20,00 & 315,58 & & & \\
\hline \multirow[t]{4}{*}{ Silahlı saldırı } & Yaşanan & 18,96 & 19,00 & 274,49 & 12,989 & \multirow{4}{*}{0,000} & \multirow{4}{*}{$\begin{array}{l}1-4 \\
2-4 \\
3-4\end{array}$} \\
\hline & Tanik olunan & 19,40 & 20,00 & 285,03 & & & \\
\hline & Her ikisi & 18,90 & 192,00 & 279,15 & & & \\
\hline & Hiçbiri & 21,26 & 21,00 & 338,23 & & & \\
\hline \multirow[t]{4}{*}{ Hafif yaralanma } & Yaşanan & 18,95 & 19,00 & 273,00 & 12,036 & \multirow{4}{*}{0,007} & \multirow{4}{*}{$\begin{array}{l}1-4 \\
2-4 \\
3-4\end{array}$} \\
\hline & Tanık olunan & 19,44 & 20,00 & 286,79 & & & \\
\hline & Her ikisi & 18,43 & 21,00 & 260,21 & & & \\
\hline & Hiçbiri & 21,11 & 22,00 & 334,93 & & & \\
\hline \multirow[t]{4}{*}{ Ağır yaralanma } & Yaşanan & 18,87 & 19,00 & 271,48 & 12,548 & \multirow{4}{*}{0,006} & \multirow{4}{*}{$\begin{array}{l}1-4 \\
2-4 \\
3-4\end{array}$} \\
\hline & Tanik olunan & 19,30 & 20,00 & 283,53 & & & \\
\hline & Her ikisi & 15,67 & 15,00 & 170,17 & & & \\
\hline & Hiçbiri & 21,04 & 21,00 & 331,54 & & & \\
\hline \multirow{4}{*}{$\begin{array}{l}\text { Yakın çevreden birinde kalıcı } \\
\text { sakatlanma/ iz bırakan } \\
\text { yaralanma }\end{array}$} & Yaşanan & 19,13 & 19,00 & 278,33 & 11,096 & \multirow{4}{*}{0,011} & \multirow{4}{*}{$1-4$} \\
\hline & Tanık olunan & 20,16 & 20,00 & 307,53 & & & \\
\hline & Her ikisi & 19,57 & 19,50 & 289,96 & & & \\
\hline & Hiçbiri & 21,74 & 22,50 & 351,94 & & & \\
\hline \multirow{4}{*}{$\begin{array}{l}\text { Yakın çevreden birinin doğal } \\
\text { olmayan/ beklenmedik vefatı }\end{array}$} & Yaşanan & 19,41 & 20,00 & 285,56 & 6,701 & \multirow{4}{*}{0,082} & \multirow{4}{*}{-} \\
\hline & Tanık olunan & 19,89 & 20,00 & 301,87 & & & \\
\hline & Her ikisi & 20,10 & 21,00 & 308,53 & & & \\
\hline & Hiçbiri & 21,80 & 22,00 & 352,14 & & & \\
\hline \multirow[t]{4}{*}{ İşkence/ dövülme } & Yaşanan & 19,62 & 19,00 & 290,76 & 14,464 & \multirow{4}{*}{0,002} & \multirow{4}{*}{$\begin{array}{l}1-4 \\
2-4 \\
3-4\end{array}$} \\
\hline & Tanik olunan & 18,99 & 19,50 & 274,70 & & & \\
\hline & Her ikisi & 19,67 & 20,00 & 297,67 & & & \\
\hline & Hiçbiri & 21,14 & 21,00 & 334,97 & & & \\
\hline \multirow[t]{4}{*}{ Rehin alınma/ tutuklanma } & Yaşanan & 19,24 & 20,00 & 285,84 & 12,286 & & \\
\hline & Tanik olunan & 19,02 & 19,00 & 274,65 & & & $1-4$ \\
\hline & Her ikisi & - & - & 69,50 & & 0,006 & $2-4$ \\
\hline & Hiçbiri & 20,73 & 21,00 & 323,53 & & & \\
\hline Cinsel şiddet & Yaşanan & 18,14 & 18,50 & 252,69 & 12,454 & & \\
\hline & Tanik olunan & 19,00 & 19,00 & 275,43 & & & $1-4$ \\
\hline & Her ikisi & - & - & 69,50 & & 0,006 & $2-4$ \\
\hline & Hiçbiri & 20,74 & 21,00 & 323,55 & & & \\
\hline
\end{tabular}




\begin{tabular}{|c|c|c|c|c|c|c|c|}
\hline \multirow[t]{4}{*}{ Mallarına el konulması/ gasp } & Yaşanan & 18,14 & 18,50 & 252,69 & 29,062 & \multirow{4}{*}{0,000} & \multirow{3}{*}{$\begin{array}{l}1-2 \\
2-4 \\
3-4\end{array}$} \\
\hline & Tanık olunan & 19,91 & 20,00 & 299,18 & & & \\
\hline & Her ikisi & 19,50 & 21,00 & 292,55 & & & \\
\hline & Hiçbiri & 21,76 & 22,00 & 350,92 & & & \\
\hline
\end{tabular}

Suriyeli Mültecilerin Yaşam Doyumlarını, Travma Sonrası Stres Bozukluğuna Sahip Olup Olmamalarna Göre Incelenmesi

Suriyeli mültecilerin travma sonrası stres bozukluğuna sahip olup olmamalarına göre yaşam doyumlarının farklılaşmasına ilişkin bulgular Tablo 4'te verilmiştir.

Tablo 4. Suriyeli mültecilerin travma sonrası stres bozukluğuna sahip olup olmamalarna göre yaşam doyumlarna ilişkin Mann Whitney U testi sonuçları

\begin{tabular}{llccclll}
\hline TSSB & $\mathrm{N}$ & $\bar{X}$ & Ortanca & Sira ort & U & Z & P \\
\hline TSSB var & 82 & 23 & 49 & 212,80 & 14047,00 & $-4,74$ & 0,00 \\
TSSB yok & 508 & 242 & 266 & 308,85 & & & \\
\hline
\end{tabular}

Tablo 4'te görülebileceği gibi, Suriyeli mültecilerin \%13,9'unda $(\mathrm{n}=82)$ TSSB tanısı bulunmakta; \%86,1'inde $(\mathrm{n}=508)$ ise TSSB bulunmamaktadır. TSSB'si olan Suriyeli mültecilerin yaşam doyum düzeyleri (Ortanca $=49$; Sıra ort $=212,80$ ) ile TSSB'si olmayan Suriyeli mültecilerin yaşam doyum düzeyleri (Ortanca $=266$; Sıra ort $=308,85$ ) arasında gözlenen fark istatistiksel olarak anlamlı bulunmuştur ( $\mathrm{U}=14047,00 ; \mathrm{z}=4,74 ; \mathrm{p}<0,01)$. Diğer ifadeyle TSSB'si olan ve olmayan katılımcıların yaşam doyum düzeyleri birbirinden farklıdır. Yani TSSB'si olanların yaşam doyumu diğerlerine göre daha düşüktür.

\section{Tartışma ve Sonuç}

Bu çalışmada Suriyeli mültecilerin çeşitli travmatik yaşantıları nasıl deneyimlediklerine (yaşama/tanık olma) göre TSSB ve yaşam doyumlarının farklılık gösterip göstermediği incelenmiştir. Araştırma sorularına ilişkin bulgular aşağıda sırayla tartışılmıştır. 
Suriyeli Mültecilerin Çeşitli Travmatik Yaşantılarn Nasıl Deneyimlediklerine (Yaşama/Tanık Olma) Göre TSSB İncelenmesine İlişkin Tartışma

Bu çalışmada, travmatik yaşantı türlerinden; ağır yaralanma, yakın çevresinden birilerinde kalıcı sakatlanma/iz bırakan yaralanma, işkence/dövülme, rehin alınma/tutuklanma, cinsel şiddet ve gasp olaylarını yaşayan/olaya tanık olan mültecilerin TSBB semptomlarının, diğer mültecilere oranla daha yüksek olduğu gözlenmiştir . Mültecilerle alakalı yapılan çalışmaların birçoğunda travmatik olaylar saptanmış ve yaşanılan/tanık olunan travmatik olayların, mültecilerin TSSB'lerini artırdığı görülmüştür. Bu çalışmalardan Acartürk (2016)'ün araştırmasına göre göç öncesindeki travmatik yaşantılar travma sonrası stres bozukluğuna yol açabilmektedir. Bazen de genel olarak göç yaşantısı travmatik bir hal alabilmekte ve bireylerde genel olarak travma sonrası stres bozukluğu belirtileri görülmesine neden olabilmektedir.

Savaş sonrası göç eden mülteciler ile yapılan bazı çalışmalarda, TSSB tanısı alan mültecilerin büyük çoğunluğun geçmişinde travmatik yaşantıları deneyimledikleri belirtilmektedir (Davis ve Davis, 2006; Letica-Crepulja, Şalcioğlu, Franciskovic ve Başoğlu, 2011; Roberts, Ocaka, Browne, Oyok ve Sondorp, 2008). Belz, Belz, Özkan, ve Graef-Calliess (2017), Alman mülteci kabul merkezinden 85 mülteci ile yürüttükleri çalışmada, mültecilerin hem kendi ülkelerinde hem de kaçtıkları ülkelerde travmatik olaylara maruz kaldıkları ve sonrasında ise mültecilerde TSSB, kaçınma, dissosiyasyon ve depresyon belirtileri gözlemlenmiştir. Kazour vd. (2017) Suriyeli mülteciler ile yürüttükleri araştırmada ise yaşam boyu TSSB oranını \%35,4 ve TSSB nokta yaygınlığ oranını \%27,2 olarak saptamışlardır.

Nitekim literatürde mültecilerin yaşadıkları ya da tanık oldukları travmatik yaşantı türü ile TSSB düzeyi arasında pozitif bir ilişki tespit eden çalışmalar, travmatik yaşantıların TSSB düzeyini önemli ölçüde arttırdığını öne sürmektedir (Aragona vd., 2012; Arnetz, Rofa, Arnetz, Ventimiglia ve Jamil, 2013; Binay, 2016; Cengiz, 2016; İbrahim ve Hassan, 2013; Sağaltıcı 2013; Yeniçeri, 2017).

Mültecilerde çatışmaya bağlı şiddet, yer değiştirme ve çoklu kayıplardan kaynaklanan TSBB yaşanması söz konusudur. Örneğin, TSSB gelişen mültecilerde en çok belirtilen travmatik deneyimleme; bir yakının ölümüne tanık olma/aile üyelerinden birinin kaybı olayıdır (Akgün, 2016; Alpak, 2005; Al- 
Shagran, Khasawneh, Ahmed ve Jarrah, 2015). Sığınılan ülkedeki yaşam koşullarına uyum problemleri, dil engelleri, zihinsel sağlık hizmeti almakla ilişkili damgalama gibi çeşitli sorunlar yaşanması TSSB gelişimini artırmaktadır (Hassan, Ventevogel, Jefee-Bahloul ve Barkil-Oteo, 2016). TSSB oranının yüksek olmasında Suriye çatışmasının süregelen doğası, ciddiyeti ve özellikle de korkunç olayların meydana gelmesi gibi faktörlerin etkili olabildiği düşünülmektedir. Görüldüğü gibi birçok çalışma bu araştırmada elde edilen sonucu desteklemektedir.

\section{Suriyeli mültecilerin çeşitli travmatik olaylam nasıl deneyimlediklerine (ya- şama/tanık olma) göre yaşam doyumlarnın incelenmesine yönelik tartışma:}

Bu çalışmanın ikinci bulgusu, travmatik olayı yaşayan/tanık olan mültecilerin yaşam doyum düzeylerinin diğerlerine göre anlamlı bir şekilde düşük olmasıdır. Veenhoven (1996) bireyin toplumda bulunduğu konum, yaşam olayları, yaşam kalitesi, kişisel yetenekler/beceriler ve tecrübeli olmayı yaşam doyumunu etkileyen değişkenler olarak görmektedir. Annak (2005) hem ruhsal hem de fiziksel sağlığın bireylerin yaşam doyumu üzerinde belirleyici bir etken olduğunu belirtmektedir. Potansiyel olarak travmatik olayların yaşanması/ olaylara tanık olunması ruh sağlı̆̆ının bozulmasına ve yaşam doyumunun azalmasınına yol açan önemli bir risk faktörüdür (Splevins, Cohen, Bowley ve Joseph, 2010). Bowen (2002), mültecilerin travmatik olaylara maruz kalmasından ötürü artan stres ile yaşam doyumunun düştüğünü belirtmektedir.

Yapılan bazı çalışmalar incelendiğinde de benzer sonuçlara ulaşıldığı görülmüştür. Bunlardan; Sleijpen, Haagen, Mooren ve Kleber (2016), Hollanda' da bulunan mültecilerin yaşam doyumunun travmatik olaylar sonucunda azaldığını, Güney Choi vd. (2017) Kore' de yaşayan Kuzey Koreli mültecilerin travmatik yaşantılarına bağlı olarak yaşam doyumlarının düştüğünü belirtmektedirler. Ayrıca daha fazla askeri şiddete maruz kalmış, şiddet olaylarına karışmış Filistinli çocukların (Veronese, Pepe, Jaradah, Al Muranak ve Hamdouna, 2017), füze saldırılarına maruz kalmış olan kişilerin (Besser ve Neria, 2009) ve Kore Savaşı sırasında travmatik olaylara maruz kalanların (Ilkin vd., 2009) yaşam doyumunun düştüğü görülmüştür.

Daha önce yapılan çalışmalar, bu çalışmadan elde edilen TSSB yaşayanların yaşam doyumunun daha düşük olduğu bulgusunu desteklemektedir. 
Suriyeli Mültecilerin Yaşam Doyumlarının, Travma Sonrası Stres Bozukluğuna Sahip Olup Ya Da Olmamalarına Göre İncelenmesine İlişkin Tartışma:

Çalışmada elde edilen bir diğer sonuç ise travma sonrası stres bozukluğuna sahip katılımcıların yaşam doyum düzeylerinin diğer katılımcılara oranla daha düşük olduğudur. Bireyde yaşam doyumunun sağlanması için belli psikolojik, sosyal, ekonomik ve kültürel koşulların mevcut olması gerekmektedir. Bir mülteci için bu koşulların oluşması en azından kısa vadede pek mümkün olmamaktadır. Bundan ötürü bireyin yaşadığı travma sonrası stres bozukluğuyla başa çıkmaya çalışırken hem kendi temel yaşam gereksinimlerini sağlamaya çalışması hem de yaşamdan doyum sağlaması zorlu bir süreç olabilmektedir. Matanov vd. (2013) savaştan etkilenen topluluklarda travma sonrası stres bozukluğu belirtilerinin bireylerin öznel yaşam kalitesi üzerinde bağımsız ve olumsuz olarak etkili olduğunu belirtmektedirler. Ayn zamanda TSSB kişilerde yaşam doyumunu etkileyip psikososyal ve mesleki işlevselliği ve genel refahını bozabilir. Schnurr vd. (2009) çalışmalarında TSSB' si olanlarda daha olumsuz yaşam koşulları ve daha düşük yaşam doyumu olduğunu belirtmektedirler.

Bu çalışmadan elde edilen bulguyu destekleyen başka çalışmaların varlığ 1 dikkat çekmektedir. Bunlardan; Karatzias vd. (2013) TSSB tanısı almış bireylerde, Bowen (2002)m stres düzeyi yüksek mültecilerde, Goff (2007) Irak ve Afganistan'da yapılan operasyonlara katılan ve şiddetli TSSB semptomları olan askerlerde yaşam doyumunun düşük olduğunu bulmuşlardır. Ayrıca Vietnam gazilerinden TSSB semptomları gözlenen gazilerde (Koenen, Stellman, Sommer ve Stellman 2008), TSSB semptomları gözlenen sığınmacı ve mültecilerde (Sleijpen vd., 2016; Choi vd., 2017) de yaşam doyumunun diğerlerine göre daha düşük olduğu bulunmuştur.

Yaşam doyumu ve TSSB üzerine yapılan çalışmalar incelendiğinde genel olarak çalışmanın bulgularının desteklendiği söylenebilir. Bu çalışmada aşağıdaki sonuçlara ulaşılmıştır:

1. Travmatik olayı yaşayan/olaya tanık olan mültecilerin TSBB düzeyleri diğerlerine göre daha yüksektir.

2. Travmatik olayı yaşayan/olaya tanık olan mültecilerin yaşam doyum düzeyleri diğerlerine göre daha düşüktür.

3. 'TSSB' si olan mültecilerin yaşam doyumlanı, TSSB' si olmayan mültecilere göre daha düşüktür. 
Bu çalışmanın sınırlılığı olarak çalışmanın temel tasarımının, mültecilerin kesitsel bir örneklemesine dayanması görülmektedir. Bu nedenle bulgular yorumlanırken dikkatli olunmalıdır. Ayrıca boylamsal çalışmalar yapılarak bu çalışmada görülmeyen değişimler incelenebilir. Mültecilerle ilgili olarak yapılan çalışmaların daha çok ruh sağlığı bozuklukları üzerinde odaklandığı görülmektedir. Bu nedenle yapılacak diğer bilimsel çalışmalarda mültecilerin ruh sağlığıyla birlikte umut, yaşam kalitesi, psikolojik dayanıklılık gibi pozitif psikoloji değişkenleri ele alınabilir. Ayrıca çeşitli psikososyal müdahale programları ve psikoeğitim programları mültecilerin uyumların olumlu etkileyecek çalışmalar olabilir. 
EXTENDED ABSTRACT

\title{
Investigation of Post-Traumatic Stress Disorder and Life Satisfaction Levels According to How Syrian Refugees Experience Various Traumatic Experiences
}

\author{
Demet Bilen - Binnaz Kiran \\ Zeki Sabah First School, Mersin University
}

In this study, a cross-sectional sample of Syrian refugees who came to Turkey after the civil war in Syria was examined whether the levels of post-traumatic stress disorder and life satisfaction differed according to how Syrian refugees experienced various traumatic experiences. However, it has been investigated whether the level of life satisfaction differs according to whether refugees have posttraumatic stress disorder or not.

The study was carried out in the central districts of Mersin province. It is believed that the four central districts where the research is carried out have different characteristics and socio-economic levels. Adult Syrian refugees living in these districts therefore constitute the study's sample. In the selection of the participants, heterogeneous distribution is taken into consideration. In order to realize the heterogeneous distribution, the study was carried out using the non-probable sampling method snowball technique. The data collection tools used in the research consist of four parts.

To examine the socio-demographic characteristics of the participants, a socio-demographic form containing personal information and consisting of a total of 7 items was used by the researchers. In the study, a list of traumatic events involving various traumatic events was used to evaluate the traumatic experiences experienced/witnessed by participants who were victims of war and migration. In addition, the Harvard Trauma Scale(HTQ) was used to evaluate the symptoms of post-traumatic stress disorder. The five-item Life Satisfaction Scale (SWLS) was used to measure the living satisfaction levels of refugees.

A pilot application was carried out with a group of 32 Syrian refugees in a district (Yenisehir) in the city center where the research would be conducted to test the intelligibility of the language and scale items used in the scales used 
to collect data. In the pilot application with this Syrian refugee, which constitutes a cross-sectional sample of the research sample, face-to-face interview method was used. With this pilot application, it has been determined that data collection tools are comprehensible and applicable. The study participants, conducted using the improbable sampling method snowball technique, consist of 590 Syrian refugees over the age of 18. Of the participants, 325 are female Syrian refugees while 265 are male Syrian refugees.

The data obtained from the participants in the research were analyzed and the findings were included. As a result of the research, it was found that the refugees who experienced/witnessed various traumatic events had significantly higher post-traumatic stress disorder levels than those who were not exposed in all other situations except the bombing of the city. Accordingly, it was determined that there was no difference in the post-traumatic symptom levels of Syrian refugees according to the bombing of the city where they lived $(\mathrm{p}>0,05)$.

In cases of hostage/detention and sexual violence, the distribution of the symptom levels of those who lived and never experienced the event, and the distribution of the symptom levels of those who witnessed and never witnessed the event showed a significant difference $(p<0,05)$. Also, when we look at the bombing of the house, a significant difference was observed between the symptom levels of those who experienced the event and those who never experienced $(p<0,05)$. When looking at the event of those who lost someone in their immediate environment, the distribution of symptom levels of those who lost one of their immediate environment and those who did not lose varies $(\mathrm{p}<0,05)$.

When the life satisfaction data obtained in the study were examined, a significant negative difference was observed between the various traumatic events and the level of life satisfaction. However, it was determined that there was no difference in the life satisfaction levels of the Syrian refugees according to the bombing of the house, the bombing of the city, and the unexpected loss of someone from their immediate environment $(p>0,05)$. As a result of the study, it is observed that the symptom levels of those who experienced, witnessed or experienced both in armed attacks, mild and severe injuries and torture/beatings events differed significantly from those who never experienced $(p<0,05)$. In cases of hostage/detention and sexual violence, it was deter- 
mined that the distribution of the symptom levels of those who lived and never experienced it, and the distribution and symptom levels of those who witnessed and never experienced, differed significantly $(p<0,05)$. There is a significant difference in the life satisfaction levels of those living in the immediate environment and those who have never experienced such an event in a near injury/trauma injury $(\mathrm{p}<0,05)$. Another question of the study was whether the level of life satisfaction of refugees varies according to whether there is post-traumatic stress disorder or not. Accordingly, the life satisfaction levels of the refugees who showed symptoms of post-traumatic stress disorder were lower than those who did not show symptoms of post-traumatic stress disorder. The findings of the study were evaluated in the discussion section within the framework of the relevant literature. As a limitation of this study, it is seen that the basic design of the study is based on a cross-sectional sampling of refugees. Therefore, caution should be exercised in interpreting the findings. In addition, longitudinal studies can be carried out and in this study, unseen changes can be examined. It is seen that studies on refugees mostly focus on mental health disorders. Therefore, in other scientific studies, positive psychology variables such as hope, quality of life and psychological resilience can be addressed along with the mental health of refugees. Increasing the effectiveness of psychosocial intervention programs studies are other suggestions.

\section{Kaynakça / References}

Abdallah, T. (1998). The Satisfaction with Life Scale (SWLS): Psychometric Properties in an Arabic-speaking Sample. International Journal of Adolescence and Youth, 7(2), 113-119.

Acartürk, C. (2016). Göç ve ruh sağlığı ilişkisi. The Journal of Academic Social Science, 25, 137-150.

Akgün, N. (2016). Suriyeli mültecilerde ruhsal iyilik hali ve ilişkili faktörlerin değerlendirilmesi. Yayınlanmamış yüksek lisans tezi, Selçuk Üniversitesi Sosyal Bilimler Enstitüsü, Konya

Alpak, G., Ünal, A., Bülbül, F., Sağaltıcı, E., Bez, Y., Altındağ, A., . . ,Savaş, H. A. (2015). Post-traumatic stress disorder among Syrian refugees in Turkey: A cross-sectional study. International Journal of Psychiatry in Clinical Practice, 19(1), 45-50. doi:10.3109/13651501.2014.961930 
Al-Shagran, H., Khasawneh , O. M., Ahmed , A. K., ve Jarrah, A. M. (2015). Posttraumatic stress disorder of Syrian refugees in Jordan. International Journal of Liberal Arts and Social Science, 3(3), 36- 48.

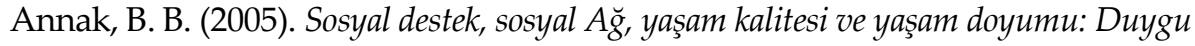
Durum ve Anksiyete Bozukluğu tanısı alan kişiler ve düzenli hemodiyaliz tedavisi gören hastalar açısından bir karşılaştırma. Yayınlanmamış yüksek lisans tezi, Mersin Üniversitesi, Mersin.

Aragona M, P. D., Aragona, M., Pucci, D., Mazzetti, M., ve Geraci , S. (2012). Postmigration living difficulties as a significant risk factor for PTSD in immigrants: a primary care study. Italian Journal of Public Health 9, 7525-1.

Arnetz, J., Rofa, Y., Arnetz, B., Ventimiglia, M., ve Jamil, H. (2013). Resilience as a Protective Factor Against the Development of PsychopathologyAmong Refugees. Journal of Nervous and Mental Disease, 201(3), 167-172.

Belz, M., Belz, M., Özkan, İ., ve Graef-Calliess, I. T. (2017). Posttraumatic stress disorder and comorbid depression among refugees: Assessment of a sample from a German refugee reception center. Transcult Psychiatry, 54(5- 6), 595- 610. doi:10.1177/1363461517745473

Besser, A., ve Neria, Y. (2009). PTSD symptoms, satisfaction with life, and prejudicial attitudes toward the adversary among Israeli civilians exposed to ongoing missile attacks. Journal of Traumatic Stress,22(4), 268-275. doi:10.1002/jts.20420.

Binay, H. (2016). Suriye ve Irak' tan gelen savaş mağduru çocuk ve genç mültecilerde travma sonrası stres bozukluğu düzeyi. Yayınlanmamış yüksek lisans tezi, Hasan Kalyoncu Üniversitesi Sosyal Bilimler Enstitüsü, Gaziantep.

Bowen, N. A. (2002). Satisfaction with life of refugees and immigrants. Doctoral Dissertation, University of Texas, Austin. http://hdl.handle.net/2152/470 adresinden alınd 1

Cengiz, İ. (2017). Suriyeli mültecilerde psikolojik örselenme, örselenme sonrası gerginlik bozukluğu, travma sonrası büyüme ve psikolojik dayanıklk. Yayınlanmamış yüksek lisans tezi. Yakın Doğu Üniversitesi, Sosyal Bilimler Üniversitesi, Lefkoşa.

Choi, Y., Lim, S. Y., Jun, J. Y., Lee, S. H., Yoo, S. Y., Kim, S., . . Kim, S. J. (2017). The effect of traumatic experiences and psychiatric symptoms on the life satisfaction of North Korean refugees. Psychopathology, 50(3), 203- 210. doi:10.1159/000468544 
Christopher, J. C. (1999). Situating psychological well-being: Exploring the cultural roots of its theory and research. Journal of Counseling $\mathcal{E}$ Development, 77(2), 141- 153.

Davis , M. R., ve Davis , H. (2006). PTSD symptom changes in refugees. Torture, 16. Diener, E. (1984). Subjective Well-Being. Psychological Buletin, 95(3), 542- 575.

Diener, E., ve Seligman, M. E. (2002). Very happy people. Psychological Science, 13(1), 81-84.

Diener, E., Emmons, R. A., Larsen, R. J. ve Griffin, S. (1985). The satisfaction with life scale. Journal of Personality Assessment, 49(1), 71-75.

Erickson, D. J., Wolfe, J., King, D. W., King, L. A., ve Sharskansky, E. (2001). Posttraumatic stress disorder and depression symptomatology in a sample of Gulf War veterans: a prospective analysis. Journal of Consulting and Clinical Psychology, 69, 41-44.

Goff, B. S. (2007). The impact of individual trauma symptoms of deployed soldiers on relationship satisfaction. Journal of Family Psychology, 21(3), 344-353.

Hassan, G., Ventevogel, P., Jefee-Bahloul, H., \& Barkil-Oteo, A. (2016). Mental health and psychosocial wellbeing of Syrians affected by armed conflict. Epidemiology and Psychiatric Epidemiology, 25, 129-141.

Ibrahim, H., ve Hassan, C. Q. (2017). Post-traumatic stress disorder symptoms resulting from torture and other traumatic events among Syrian Kurdish refugees in Kurdistan region, Iraq. Frontiers in Psychology, 8(241).

Ilkin, J. F., Sim, M. R., Mckenzie, D. P., Horsley, K. W., Wilson, E. j., Harrex, W. K., ... Henderson, S. (2009). Life satisfaction and quality in Korean War veterans five decades after the war. Journal Epidemiology and Community Health, 63, 359-365. doi:10.1136/jech.2007.061986

Johnson, H., ve Thompson, A. (2008). The development and maintenance of post traumatic stress disorder (PTSD) in civilian adult survivors of war trauma and torture: a review. Clinical Psychology Review, 28, 36-47.

Karatzias, T., Chouliara, Z., Power, K., Brown, K., Begum, M., McGoldrick, T., ve MacLean, R. (2013). Life satisfaction in people with post-traumatic stress disorder. Journal of Mental Health, 22(6), 501-508.

Kazour, F., Zahreddine, N. R., Maragel, M. G., Almustafa, M. A., Soufia, M., Haddad, R., ve Richaa, S. (2017). Post-traumatic stress disorder in a sample of Syrian refugees in Lebanon. Comprehensive Psychiatry, 41-47. 
Koenen, K. C., Stellman, S. D., Sommer, J. F., ve Stellman, J. M. (2008). Persisting posttraumatic stress disorder symptoms and their relationship to functioning in Vietnam veterans: a 14-year follow-up. Journal of Traumatic Stress, 21, 49- 57

Letica-Crepulja, M., Şalcıoğlu, E., Franciskovic, T., ve Başoğlu, M. (2011). Factors associated with posttraumatic stress disorder and depression in war survivors displaced in Croatia. Croatian Medical Journal, 52(6), 709-717. doi:10.3325/cmj.2011.52.709

Lyubomirsky, S., King, L.,ve Diener, E. (2005). The benefits of frequent positive affect: Does happiness lead to success?, Psychological Bulletin, 131, 803-855.

Matanov, A., Giacco, D., Bogic, M., Ajdukovic, D., Franciskovic, T., Galeazzi, G. M., ... Priebe, S. (2013). Subjective quality of life in war affected populations. BMC Public Health, 13(624).

Mollica , R. F., Caspi-Yavin, Y., Bollin, P., Truong, T., Tor , S., ve Lavelle , J. (1992). The Harvard Trauma Questionnaire: Validating a cross-cultural instrument for measuring torture, trauma, and posttraumatic Stress disorder in Indochinese refugees. The Journal of Nervous and Mental Disease,180,111-116.

Mollica, R., Mcdonald, L., Massagli, M., ve Silove, D. (2004). Measuring trauma, measuring torture: Instructions and guidance on the utilization of Hopkins Symptom Checklist-25 (HSCL-25) and the Harvard Trauma Questionnaire (HTQ). Cambridge, MA:Harvard Program in Refugee Trauma.

Özgen, F., ve Aydın, H. (1999). Travma sonrası stres bozukluğu. Klinik Psikiyatri Dergisi, 1, 34- 41.

Pavot, W., ve Diener, E. (1993). Review of the Satisfaction With Life Scale. Psychological Assessment, 5, 164-172.

Roberts , B., Ocaka , K. F., Browne, J., Oyok , T., ve Sondorp , E. (2008). Factors associated with post-traumatic stress disorder and depression amongst internally displaced persons in northern Uganda. BMC Psychiatry, 8(38).

Sağaltıı, E. (2013). Suriyeli mültecilerde travma sonrası stres bozukluğu taraması. Yayınlanmamış Uzmanlık Tezi, Gaziantep Üniversitesi Tıp Fakültesi, Gaziantep.

Schnurr, P. P., Lunney, C. A., Bovin, M. J., ve Marx, B. P. (2009). Posttraumatic stress disorder and quality of life: Extension of findings to veterans of the wars in Iraq and Afghanistan. Clinical Psychology Review, 29, 727- 735. 
Shoeb, M., Weinstein, H., ve Mollica, R. (2007). The Harvard Trauma Questionnaire: Adapting a Cross- Cultural Instrument for Measuring Torture, Trauma and Posttraumatic Stress Disorder in Iraqi Refugees. International Journal of Social Psychiatry, 53, 447- 463.

Sleijpen, M., Haagen, J., Mooren, T., ve Kleber, R. J. (2016). Growing from experience: an exploratory study of posttraumatic growth in adolescent refugees. European Journal of Psychotraumatology, 7, Article ID 28698.

Solomon, Z., Weisemberg, M., Schwarzwald, J., ve Milkulincer , M. (1987). Posttraumatic stress disorder among soldiers with combat-stress reaction: the 1982 Israeli experience. American Journal of Psychiatry, 144, 448-454.

Splevins, K., Cohen, K., Bowley, J., ve Joseph, S. (2010). Theories of posttraumatic growth: Cross-cultural perspectives. Journal of Loss and Trauma, 15(3),259-277.

Suldo, S. M., ve Huebner , E. S. (2004). Does life satisfaction moderate the effects of stressful life events on psychopathological behavior during adolescence? School Psychology Quarterly, 19(2), 93- 105.

UNHCR. (2018a). Suriye acil durumu. 17.06.2018 tarihinde http://www.unhcr.org/tr/suriye-acil-durumu adresinden alınd1.

UNHCR. (2018b). Türkiye'de UNCHR. 18.06.2018 tarihinde http://www.unhcr.org/tr/turkiyede-unhcr adresinden alındı.

UNHCR. (2018c). Türkiye'deki mülteciler ve sı̆̆ınmacılar. 17.06.2018 tarihinde http://www.unhcr.org/tr/turkiyedeki-multeciler-ve-siginmacilar adresinden alınd1.

Veenhoven, R. (1996). Happiness and Freedom: The merits of multiple choice society. 26th International Conference of Psychology. Montreal: Canada.

Veronese, G., Pepe, A., Jaradah, A., Al Muranak, F., ve Hamdouna, H. (2017). Modelling life satisfaction and adjustment to trauma in children exposed to ongoing military violence: An exploratory study in Palestine. Child Abuse $\mathcal{E}$ Neglect , 63, 61-72.

Vindbjerg, E., Carlsson, J., Mortensen, E. L., Elklit, A., ve Makransky, G. (2016). The latent structure of post-traumatic stress disorder among Arabic-speaking refugees receiving psychiatric treatment in Denmark. BMC Psychiatry, 16(309). doi: 10.1186/s12888-016-0936-0.

Yeniçeri, A. (2017). Hatay'da yaşayan Suriyeli sı̆̆ınmacılarda travma sonrası stres bozukluğu ve depresyon. Yayınlanmamış uzmanlık tezi. Mustafa Kemal Üniversitesi, Tayfur Ata Sökmen Tıp Fakültesi, Hatay 


\section{Kaynakça Bilgisi / Citation Information}

Bilen, D. ve Kıran, B. (2020). Suriyeli mültecilerin çeşitli travmatik yaşantıları nasıl deneyimlediklerine göre travma sonrası stres bozukluğu ve yaşam doyum düzeylerinin incelenmesi. OPUSUluslararası Toplum Araştırmaları Dergisi, 15(26), 3965-3987. DOI: 10.26466/opus.658813 